\title{
Learning about stress from building, drilling and flying: a scoping review on team performance and stress in non-medical fields
}

Femke S. Dijkstra ${ }^{1,2^{*}}$ (D), Peter G. Renden ${ }^{3,4}$, Martijn Meeter ${ }^{1}$, Linda J. Schoonmade ${ }^{5}$, Ralf Krage ${ }^{6}$, Hans van Schuppen ${ }^{7}$ and Anne de la Croix ${ }^{8}$

\begin{abstract}
Background: Teamwork is essential in healthcare, but team performance tends to deteriorate in stressful situations. Further development of training and education for healthcare teams requires a more complete understanding of team performance in stressful situations. We wanted to learn from others, by looking beyond the field of medicine, aiming to learn about a) sources of stress, b) effects of stress on team performance and c) concepts on dealing with stress.

Methods: A scoping literature review was undertaken. The three largest interdisciplinary databases outside of healthcare, Scopus, Web of Science and PsycINFO, were searched for articles published in English between 2008 and 2020. Eligible articles focused on team performance in stressful situations with outcome measures at a team level. Studies were selected, and data were extracted and analysed by at least two researchers.

Results: In total, 15 articles were included in the review (4 non-comparative, 6 multi- or mixed methods, 5 experimental studies). Three sources of stress were identified: performance pressure, role pressure and time pressure. Potential effects of stress on the team were: a narrow focus on task execution, unclear responsibilities within the team and diminished understanding of the situation. Communication, shared knowledge and situational awareness were identified as potentially helpful team processes. Cross training was suggested as a promising intervention to develop a shared mental model within a team.
\end{abstract}

Conclusion: Stress can have a significant impact on team performance. Developing strategies to prevent and manage stress and its impact has the potential to significantly increase performance of teams in stressful situations. Further research into the development and use of team cognition in stress in healthcare teams is needed, in order to be able to integrate this 'team brain' in training and education with the specific goal of preparing professionals for team performance in stressful situations.

Keywords: Teams, Stress, Team performance, Performance psychology, Critical care, Emergency care, Crew resource management, Human factors

\footnotetext{
* Correspondence: f.s.dijkstra@vu.n

'Department of Educational Sciences, Vrije Universiteit Amsterdam, Van der Boechorststraat 7, Amsterdam, the Netherlands

${ }^{2}$ Academy of Health Sciences, Saxion University of Applied Sciences, Handelskade 75, Deventer, the Netherlands

Full list of author information is available at the end of the article
}

(C) The Author(s). 2021 Open Access This article is licensed under a Creative Commons Attribution 4.0 International License, which permits use, sharing, adaptation, distribution and reproduction in any medium or format, as long as you give appropriate credit to the original author(s) and the source, provide a link to the Creative Commons licence, and indicate if changes were made. The images or other third party material in this article are included in the article's Creative Commons licence, unless indicated otherwise in a credit line to the material. If material is not included in the article's Creative Commons licence and your intended use is not permitted by statutory regulation or exceeds the permitted use, you will need to obtain permission directly from the copyright holder. To view a copy of this licence, visit http://creativecommons.org/licenses/by/4.0/ The Creative Commons Public Domain Dedication waiver (http://creativecommons.org/publicdomain/zero/1.0/) applies to the data made available in this article, unless otherwise stated in a credit line to the data. 


\section{Introduction}

Healthcare professionals, especially in emergency and critical care, regularly find themselves in situations in which they have to treat patients, with colleagues from different disciplines, under different types of pressure [1], for example during cardiopulmonary resuscitation (CPR) or trauma resuscitation. Although work routines for situations such as CPR are highly standardized [2], teams have to be able to react to unexpected events. It is precisely during those unexpected events that the quality of non-technical skills (e.g. leadership, communication, teamwork) plays a decisive role for patient safety [3]. For instance, Krage et al. [4] showed that during CPR with external distractors (e.g. noise or presence of family members), the quality of non-technical skills decreased, due to the influence of stress during these situations. Hence, they argued that medical teams should adopt interventions that improve the quality of non-technical skills in stressful situations [4]. A significant factor in these situations is stress: stress can be described as an imbalance between situational demands and personal resources, and can be either beneficial or destructive to performance $[5,6]$. Thus far, many studies have shown that performance often deteriorates under stress or high pressure [7-10]. Since stress is unavoidable in healthcare, even when preventative measures are taken, patient care might benefit from team performance improvement strategies.

Research on teams within healthcare has looked into the relevant competences for teamwork in order to improve patient safety $[11,12]$. Most of this research concentrates on the acute care setting and demonstrates there is room for improvement concerning team performance in stressful situations. Ranging from the potential role of psychological skills in order to reduce the effect of stress, to the impact of certain training methodologies on stress levels within teams, multiple studies show a specific interest in stress [4, 13-16]. However, the essentials for team performance in stressful situations remain somewhat unclear and require further investigation.

This might also apply for the different training methodologies that have increasingly been used in certain fields within healthcare, for example crew resource management (CRM) and simulation training [17]. An important similarity in these training methodologies is the focus on non-technical skills, such as communication, shared understanding and situational awareness [18]. Different reviews show a tremendous amount of knowledge on these specific training methodologies [17, 19, 20]. Yet, specific requirements for team performance in stressful situations appear to be uncharted territory.

We believe that inspiration from fields outside of medicine can help with further development of training and education for health care teams, by increasing understanding of team performance in stressful situations. In a broader context, this has already led to improved quality and safety of healthcare [21, 22]. However, in order to create a more profound understanding of stress, the potential effects of stress and specifically the relationship with team performance, it could be worthwhile to explore the scope of knowledge and good examples outside the field of healthcare once again. We hope to unlock insights on team performance and stressful situations.

In this review we take a careful and systematic look beyond healthcare to learn about teams, stress and performance. We aim to provide a comprehensive overview of a) sources of stress (what is the cause?), b) effects of stress on teams (what happens?) and c) concepts on dealing with stress (what helps?). This may confirm already existing ideas or could suggest new insights into how to study, teach and train teams in healthcare and ultimately improve patient safety.

\section{Methods}

We used a scoping review methodology [23] for a broad analysis of the concept of stress among teams in disciplines outside of healthcare. The scoping review methodology systematically surveys an area of research within all types of studies, with the focus on identification and/ or clarification of important factors related to a certain concept [24]. The five steps described by Arksey and O'Malley for conducting a scoping review $[25,26]$ were used in combination with the Preferred Reporting Items for Systematic Reviews and Meta-analyses (PRISMA) and the PRISMA-ScR (scoping review) statement [27, 28].

Scoping reviews are not eligible for registration in the Prospero-database [29].

\section{Literature search and study design}

In order to cover the broadest range of interdisciplinary literature, best fitting to our research question, we searched the following bibliographic databases Scopus, Web of Science Core Collection and PsycINFO (via Ebsco), selecting articles published in English between January 1st 2008 and October 27th 2020, in collaboration with a medical librarian $(L S)$. Sources of evidence that were considered for inclusion were articles, articles in press, and reviews.

Since our pilot search with the terms 'stress', 'team' and 'performance' already returned many results, we chose to restrict ourselves to a date limit of 10 years (2008-2018, update search in 2020). Search terms included controlled terms (Thesaurus terms in PsycINFO), as well as free text terms. The following terms were used (including synonyms and closely related words) as index terms or free-text words: 'team', 'stress', 'coping' and 
'performance'. The full search strategies for all databases can be found in Supplementary File 1.

\section{Study selection}

A first selection of retrieved articles was done based on title alone (by $P R$ and $F D$ ), in order to exclude studies relating to non-humans, or stress-related physical or psychological disorders, for example. Abstracts were independently reviewed (by $A C$ and $F D$ ) using Covidence, possible discrepancies were discussed and consensus was reached.

For inclusion in the last step, review of full-text, the article needed to:

- Focus on teams working together in realistic stressful or high-pressure situations;

- Focus on the effects of stress on team performance, or focus on the appraisal of and coping with stress;

- Include the outcome measure: experienced stress or pressure by the team

A complete overview of the inclusion / exclusion criteria throughout the steps mentioned above can be found in Supplementary File 2. Every step in the screening process was done by at least two members of the interprofessional research team and discussed within the full team.

\section{Data-extraction \& analysis}

The data extraction form was designed on the basis of the research questions. After a pilot session some adaptations were made, which resulted in the final data extraction form that can be found in Supplementary File 3.

Analysis started with the facts from the data charting form. Frequent recurring themes such as shared mental model were highlighted and discussed within the team. In order to create more focus the in-depth analysis addressed potential leads for educational interventions.

The qualitative content analysis was an iterative process, in which the team often discussed topics found in the data. A final synthesis of the data was done by two researchers (by $A C$ and $F D$ ), resulting in the three main themes as seen in the results: conceptualizing stressors (what is the cause?), effect of stress on team performance (what happens?), and helpful team processes in stressful situations (what helps?) [28, 30].

We performed a critical appraisal of the studies based on a general checklist by Hawker et al. [31]

\section{Results}

The full search (see Fig. 1) yielded 9095 studies (including duplicates), with topics ranging from papers about stress in pineapple trees to the potential threat of nuclear weapons. After excluding irrelevant studies following the screening process described in the Methods section, 15 articles were identified to be included in the final analysis.

Table 1 shows descriptive characteristics of the studies included (partially based on NICE-algorithm for classifying quantitative study designs [32] and Hawker et al. [31]); Table 2 shows the specifics on stress, teams, performance and training.

\section{Conceptualizing stressors - what is the cause?}

In the fifteen papers, a myriad of terms was used for stress, often inconsistently, among which mental stress [35], tension [38], and crisis [37, 39, 42, 44, 47]. These terms all referred to situations or feelings in which demands exceeded the resources of the individual or the team. The sources of stress found in the data could be categorized as at least three non-mutually exclusive types: 1) performance pressure; 2) role pressure; and 3) time pressure.

\section{Performance pressure}

Teams can feel a shared responsibility for results, accompanied by close examination and evaluation by supervisors and clients, and associated consequences (such as a financial bonus) of the end-result of a project [33, $41,43,46]$. This type of pressure can be perceived as an external force imposed on the team.

\section{Role pressure}

A team of students with no awareness of their team members' expertise was at risk of experiencing role pressure [38]. Role pressure could be described as doubt in team members about their own role and/or the role of others, due to ambiguity, conflict or overload in task requirements [34, 36, 38, 40].

\section{Time pressure}

This type of pressure was presented as an external demand for the team to accomplish tasks within a fixed time period [35-37, 39, 42-44, 47]. Although time is an objective measure, team members can perceive time pressure differently. This subjectivity relates to why time pressure was experienced as a challenge stressor as well [40].

Terms like 'uncertainty', 'challenge' and 'threat' were described as the resulting feeling within teams when they experienced one of the stressors mentioned before. Uncertainty related to roles [34, 38, 40, 44] or the situation [37, 39, 44, 47]. Threat was the perception that some element in the environment might cause harm to the individual $[38,40]$. When perceiving a situation as a challenge, individuals and teams felt more motivated to fulfil the job [40]. 


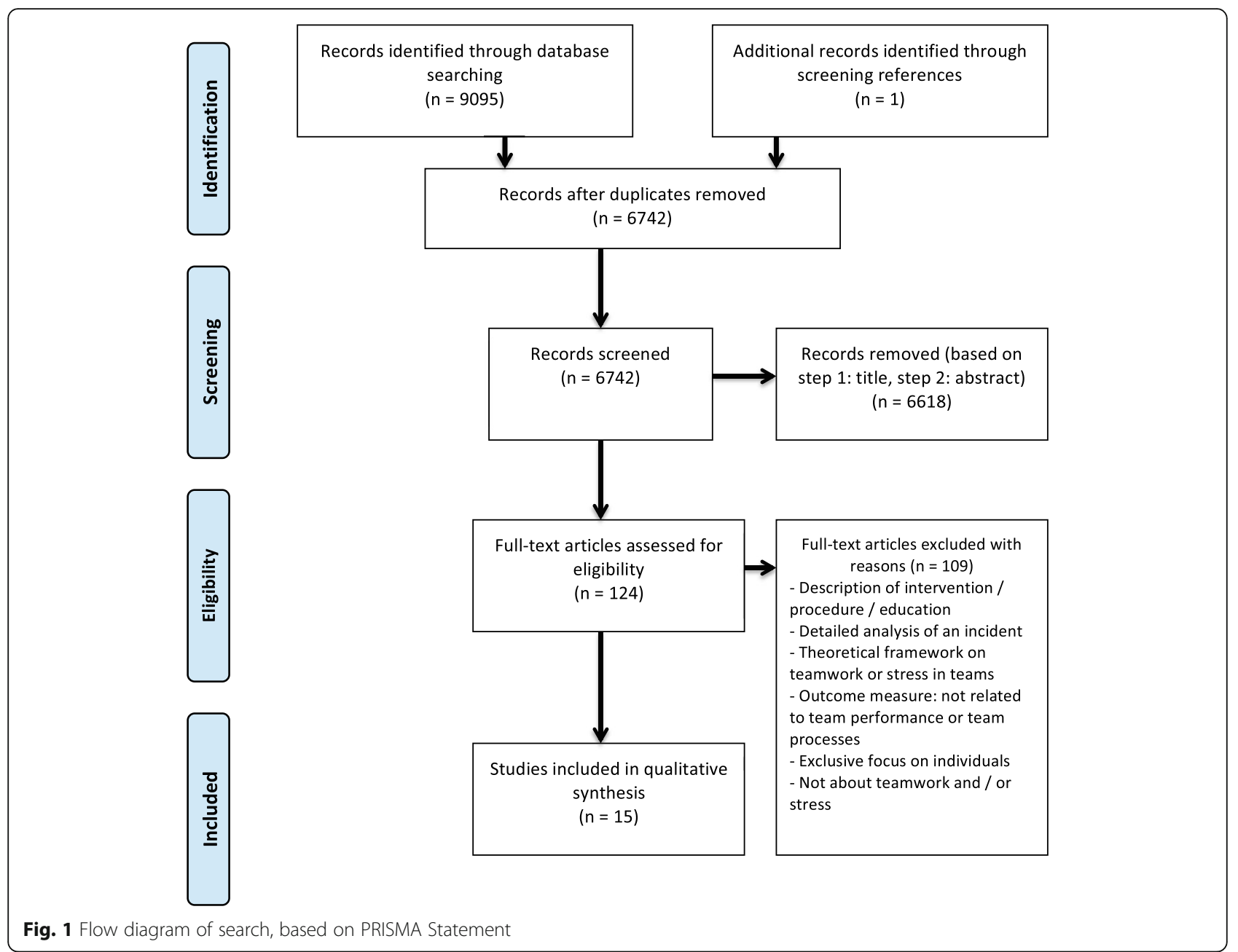

Effect of stress on team performance - what happens? Teams experiencing stress reportedly felt the effects in numerous ways, with impairing effects predominating in the included studies. A narrow focus, unclear responsibilities, diminished understanding of the situation and emotional effects were considered to be the major consequences of working in a stressful environment.

\section{A narrow focus}

Several teams exhibited a specific focus on task execution, which moved their attention away from secondary team processes like coordination, planning and team learning [43]. Members from nuclear power plant crews acknowledged this narrowing focus as a potential cause for coordination breakdowns as well [47]. Especially in stressful circumstances like simultaneous technical failures during a flight, a tendency towards task execution alone resulted in more rigid behaviour of a team and a potential decline in team performance [37].

\section{Unclear responsibilities}

In order to be flexible as a team, expertise of all team members should be known, acknowledged, and used at the right moment $[33,40]$. Due to not knowing who knows what, and who is responsible for what a decline in team performance was observed in student teams [36, $38,46]$ and navy teams $[44,45]$ and mentioned by members of nuclear engineering teams [47].

\section{Diminished understanding of the situation}

Due to inaccuracies in understanding between team members, the way information was distributed within a team could change [37, 41, 42]. A decrease in situational understanding was explicitly seen in research on action teams composed of students who were not previously acquainted with each other [38]. Without receiving necessary information for certain actions, team members were not able to anticipate what was needed in that particular situation [38]. 


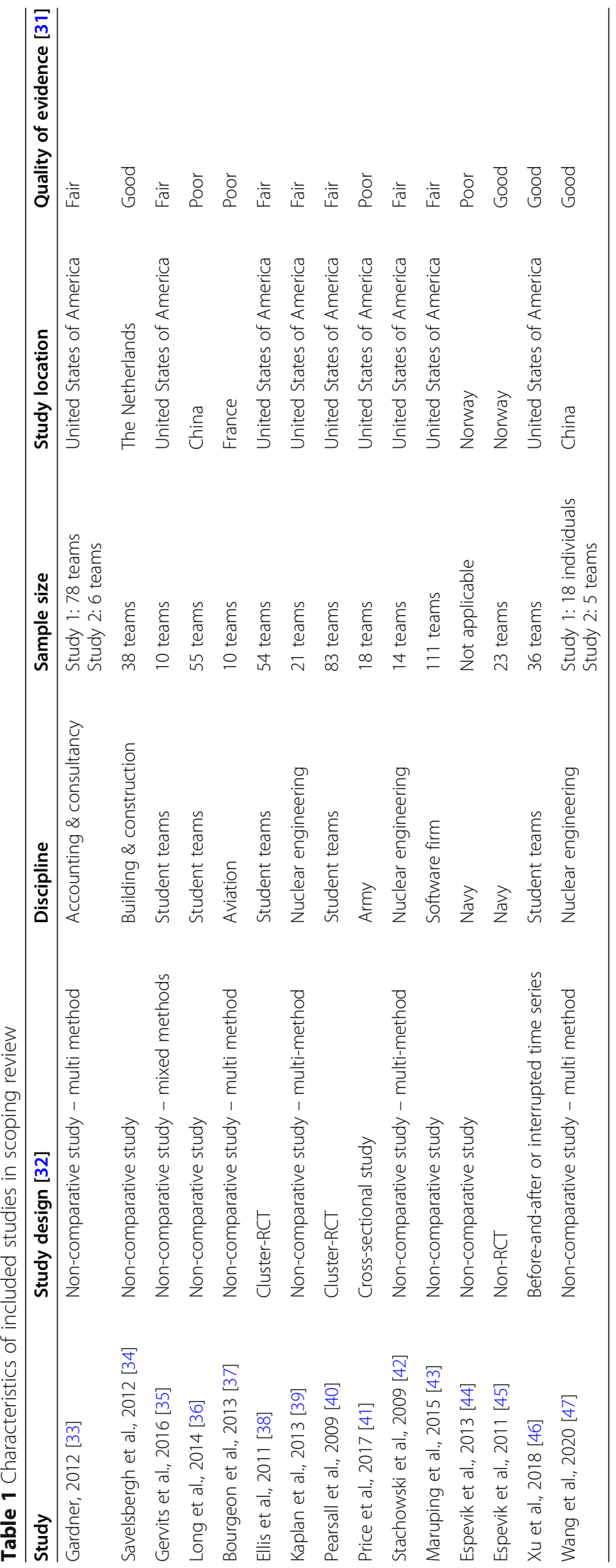




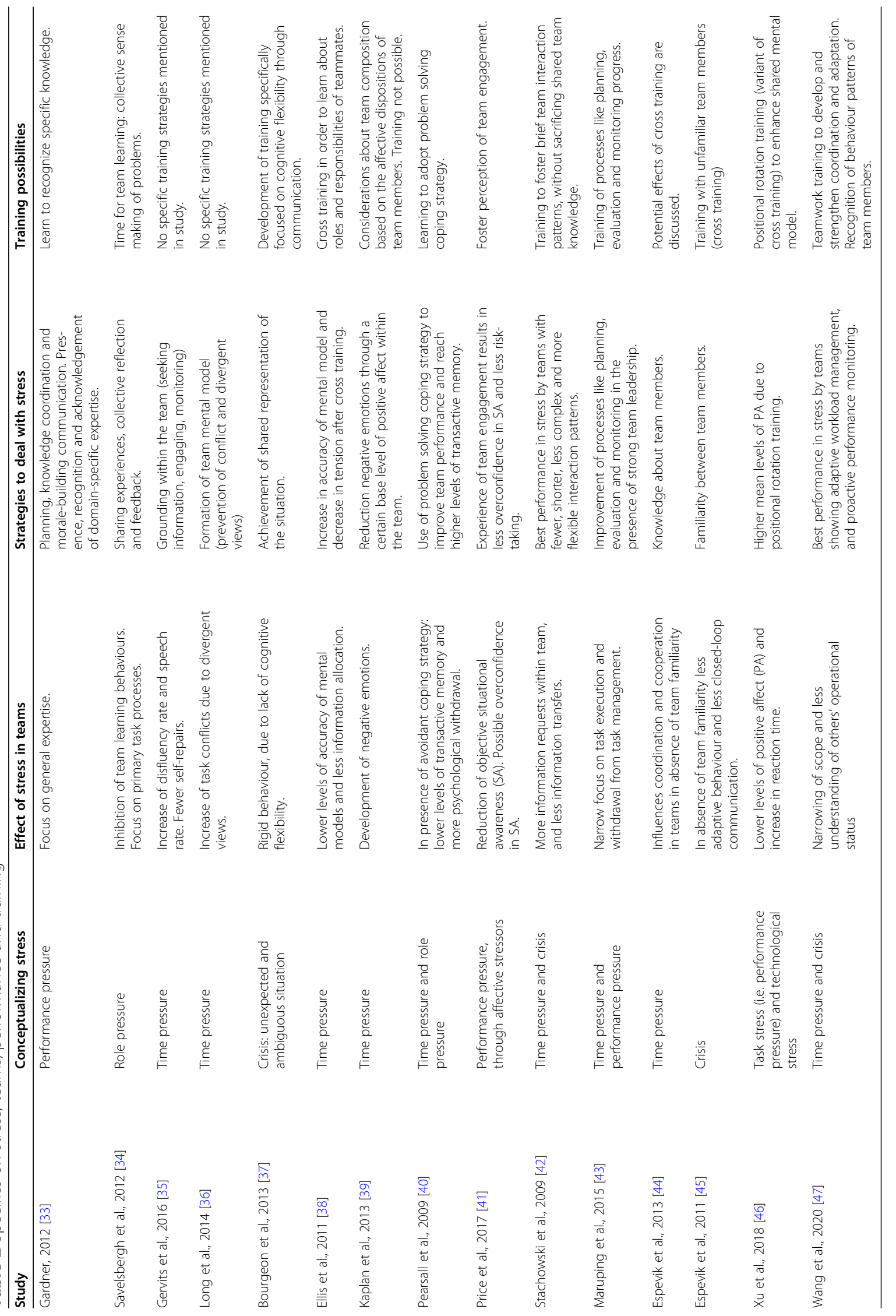




\section{Emotional effects}

The average level of emotions in nuclear power plant teams appeared to impact the performance of a team in a stressful setting $[39,46]$. Presence of a wide array of emotions was negatively related to the awareness of what was happening around the teams, the management of their cognitive resources, the exchange of information and their collaboration [39].

\section{Helpful team processes in stressful situations - what helps?}

Helpful team processes were observed to maintain or even improve team performance in stressful situations. Three main topics retrieved from the included articles are communication, shared understanding and knowledge, and situational awareness.

\section{Communication}

In terms of building morale [33], familiarizing with the team [35], preventing conflicts [36] and regulating the content of information [37], communication is essential.

In nuclear power plants, with crews responding to a simulated crisis event, the best performing teams showed specific communicative characteristics: interaction patterns involving fewer team members, and using short phrases instead of complex interactions [42]. Moreover, in a study of teams working on a collaborative task in a time pressure situation, corrections in speech and closed loop communication increased their shared understanding and knowledge [35].

\section{Shared understanding and knowledge}

Teams with the opportunity to get acquainted with each other in preceding trainings, showed better performance, more efficiency and more resilience in a stressful simulated training [45]. Particular knowledge about team members, concerning their expertise, skills, abilities and preferences seemed useful. This is captured in the term shared mental model (SMM) defined as 'a shared organized understanding and mental representation of key elements of the teams' relevant environment' [44]. This understanding could be optimized by investing time in exploring possibilities to reflect on the division of roles [34]. Additionally, by sharing experiences teams may be equipped with the flexibility to adapt to a changing and unpredictable environment [34]. This need for adaptive behaviour was exhibited by leaders of nuclear power plant crews as well: their teams showed better performances in simulated training sessions than the teams with less flexible and adaptive behaviour [47].

Closely related to shared mental model is knowing what others in the team know, for which the term 'transactive memory' is used, defined by Austin [48], as cited in Pearsall et al. [40]: 'a combination of knowledge possessed by each individual, and a collective awareness of where knowledge resides within the team'. Improvements in transactive memory were seen when teams dealt with challenge stressors with a problem solving coping strategy [40]. The appraisal of challenge stressors was an opportunity for growth as a team, through which team members were informed of and learned from each other's knowledge [40].

\section{Situational awareness}

Working successfully in a certain environment means accurately perceiving and understanding this environment. This perception and understanding is defined as situational awareness [41]. A measure of situational awareness was whether or not team members recognized a need for information with their colleagues [38]. Teams who anticipated better on this information need performed in a more efficient way than teams with lower levels of anticipation [38, 47].

In contrast with an adequate understanding of a situation, overconfidence in situational awareness has also been described [41]. Team members could feel they are in command of a situation (subjective SA), but in fact they are not (objective SA): overconfidence in situational awareness is present. In a team of soldiers, team members with a high level of subjective SA, but low levels of objective SA could feel overconfident, resulting in an increase in risk-taking and a possible decline in team performance [41]. A feeling of team engagement within the team prevented team members from feeling overconfident, resulting in less risk-taking in a stressful simulated scenario [41]. Thus, team engagement may help in reaching adequate situational awareness.

\section{Training possibilities for teams}

The possibility of training teams for stressful situations was discussed explicitly in three studies that focused on cross training [38, 45, 46]. Cross training is a practice where teams can experience the different roles and tasks of each member through hands-on training [46]. Two studies reported positive effects of cross training, ranging from an overall more positive affective experience on the team level in comparison to another training methodology [46], and an increase in the accuracy of shared mental models [38]. The third study, with teams of naval cadets, focused mainly on the phenomenon of team familiarity: comprehensive knowledge on individual differences in competencies, skills, and abilities within the team [45]. Both teams with and without team familiarity were trained through cross training, and it seemed that teams with team familiarity were better at identifying changes in the team and their teammates [45].

More general comments on training were made in the remaining articles, ranging from the importance of 
fostering the perception of team engagement [41] to training in order to promote brief team interaction patterns [42].

\section{Discussion}

\section{Main findings}

Through this scoping review we have learned valuable lessons on team performance in stressful situations from disciplines outside the field of healthcare. Our main goal was to deepen our understanding of the concept of stress and its effects on team performance, and strategies and potential interventions to deal with stress. Because the psychological effects of stress are generic, and scientific insights and innovative strategies are sometimes more advanced in fields outside of medicine, we feel that it is important to learn from these fields.

We found a myriad of study designs in the included articles, and many studies were multi- or mixed methods, signifying the complexity of the topic. Sources of stress found in the data could be categorized as performance pressure, role pressure and time pressure. The main effects of these stressors on teams were at a cognitive level: a narrowing of focus, diminished understanding of the situation and uncertainty in roles and responsibilities. To support or improve team performance in stressful situations, situational awareness, transactive memory and a shared mental model were considered important. Investing time in proficient communication during team performance under pressure might result in improvement of these cognitive outcomes. This is backed up by previous research about rudeness and incivility and their adverse consequences on team performance $[49,50]$. An intervention investigated in several included studies is cross training. Cross training was found to increase knowledge about team members, and might lead to an improved shared mental model.

\section{The 'team brain'}

Three of the themes we found showed overlap, namely: situational awareness, transactive memory and shared mental model. A key resemblance is that these three revolve around the development of a common view of the situation, for which communication is important. We would like to introduce the term 'team brain' as an umbrella term under which these themes come together.

In previous medical research, authors have talked about team cognition as an important asset for teamwork [51-53]. Team mental models and transactive memory support a team in the adaptation to sudden changes in the condition of a patient [52]. For example, surgery residents exhibited SMM-development with other team members after participating in a stressful simulation scenario (e.g. fire in the operating room during a laparoscopic task) [54]. Simulation training might have the potential to develop these cognitive structures [54]. After being involved in a trauma simulation, professionals in the emergency department showed an increase in transactive memory, which was associated with improved team performance as well [55]. An integration of the three cognitive themes and team performance in stressful situations has not yet been specified.

Three of the included studies $[38,45,46]$ investigated cross training as a useful intervention for teams to improve their teamwork in stressful situations. We are aware of only a few studies within the medical field mentioning cross training as a useful intervention [5660]. However, the results from our included studies suggest the effectiveness of this type of training, specifically the positional rotation variant where team members act in the role of their colleagues for a short time [38, 46]. Knowledge about the roles of your team members could add to the development of a 'team brain'.

\section{Leads for training and further research}

Interprofessional training of ad hoc teams in healthcare has gained a lot of interest and progression over the past few years [19, 61-63]. These trainings often focus on behaviour, aiming to follow a certain algorithm for a specific clinical scenario like CPR. Our review suggests that for an affective process like stress, shared cognition of a team could also be a valuable focus of training. Development of a team brain, consisting of a shared mental model, situational awareness and transactive memory, could lead to an increase in team performance in stressful situations and subsequently improve patient outcomes $[64,65]$.

The diverse use of concepts like shared mental model, situational awareness and transactive memory calls for a clear definition that can be used to implement them in training methodologies. A recent review on shared mental models [59] confirms that a clear definition of this important cognitive outcome is still lacking. Floren et al. argued that consistent use of a definition is necessary to design and evaluate interventions that can improve collaboration of healthcare professionals [59]. Our research does not specifically address this point, but does emphasize the importance of a team brain when working under stressful circumstances. Future studies could focus on further clarification of this concept and how it can positively affect team performance of medical teams. Interventions that might contribute to the development of a team brain in an ad hoc team are possible further areas for future research. Reid et al. proposed a "Zero Point Survey" to further improve safety and performance during resuscitation [66]. They showed that an extra readiness check of self, team and environment, right before the primary survey of the patient, followed by an update 
and priorities, could help in developing a shared mental model. Interesting interventions like these warrant further research.

The different studies on cross training included in this review have shown the potential positive effect of this training methodology. However, by quickly scanning the literature on healthcare teams and cross training, we found a lack of studies specifically focusing on the effect of cross training in ad hoc teams working in stressful conditions. This might be an interesting topic for future research, specifically the role of cross training in the development of a 'team brain'.

\section{Limitations}

We found a small number of articles eligible for our review. Our initial search yielded many studies examining teamwork, but study outcomes often were described at an individual rather than team level or did not consider the effects of stress. Therefore, our strict eligibility criteria may have resulted in a restricted number of included studies on the concepts of stress and team performance. However, it does provide us with the insight that this topic requires more thorough research, which is in line with Groombridge et al. who studied decision-making during a potential stressful situation like CPR [67].

Although a thorough search was conducted, there is a possibility we missed articles on the topic. Our search was restricted to three databases (PsycINFO, Web of Science and Scopus), and to English articles only. Nonetheless, we believe the studies included in our review shed a different light on the topic, especially since our search has come up with "out of the box" journals.

We did not include studies from medical professions, and there was a lot of diversity in quality and design of the included studies. This could be interpreted as a lack of rigour. However, our novel way of looking at team performance under stress aimed to unlock potential new insights, and to learn from other disciplines. We believe our results achieved to do so. Moreover, we think the diversity of study designs implies that the study of stress and team performance is complex, multi-faceted, and warrants further research. Finally, the diversity of backgrounds within the interprofessional research team could be worthwhile and provide the reader with a different view.

\section{Conclusion}

Critical patients demand the highest level of care by emergency teams. At the same time, stress can decrease team performance dramatically. By looking beyond the discipline of healthcare, we gain valuable insights in the effect of stress on team performance. Stress can be caused by performance pressure, role pressure and time pressure and has negative effects on focus, clear vision of responsibilities and an understanding of the situation. We have shown that detrimental effects of stress on team performance may be mitigated through development of a 'team brain'. Such a 'team brain' could encompass situational awareness, transactive memory and shared mental model, which are necessary for excellent team performance in stressful situations. Communication connects these themes within the team. Further research into the development and use of this 'team brain' in stressful situations is needed to be able to integrate the concept in training and education, to create the high-performance team our patients need.

\section{Abbreviations \\ CPR: Cardiopulmonary resuscitation; CRM: Crew resource management; PRIS MA: Preferred reporting items for systematic reviews and meta-analyses; SA: Situational awareness; PA: Positive affect; SMM: Shared mental model}

\section{Supplementary Information}

The online version contains supplementary material available at https://doi. org/10.1186/s13049-021-00865-7.

\section{Additional file 1.}

Additional file 2.

Additional file 3.

Acknowledgements

Not applicable.

\section{Authors' contributions}

FD was responsible for the study design, literature search, data extraction, study quality assessment and manuscript preparation. AC contributed to the study design, data extraction, study quality assessment and manuscript preparation. $P R$ and $M M$ contributed to the study design, data extraction and manuscript preparation. LS contributed to the literature search and manuscript preparation. RK and HS contributed to manuscript preparation. FD takes responsibility for the paper as a whole. The author(s) read and approved the final manuscript.

\section{Funding}

This research is funded by the Dutch Research Council (NWO), grant number 023.009.064.

\section{Availability of data and materials}

All data generated or analysed during this study are included in this published article (and its supplementary information files).

\section{Declarations}

Ethics approval and consent to participate

Not applicable.

Consent for publication

Not applicable.

Competing interests

The authors declare that they have no competing interests.

\section{Author details}

'Department of Educational Sciences, Vrije Universiteit Amsterdam, Van der Boechorststraat 7, Amsterdam, the Netherlands. ${ }^{2}$ Academy of Health Sciences, Saxion University of Applied Sciences, Handelskade 75, Deventer, the Netherlands. ${ }^{3}$ Faculty of Health, Nutritrion and Sport, The Hague University of Applied Sciences, Johanna Westerdijkplein 75, The Hague, the 
Netherlands. ${ }^{4}$ Department of Human Movement Sciences, Vrije Universiteit Amsterdam, Van der Boechorststraat 7, Amsterdam, the Netherlands. ${ }^{5}$ Medical library, Vrije Universiteit Amsterdam, De Boelelaan 1117, Amsterdam, the Netherlands. ${ }^{6}$ Department of Anesthesiology, KJF Klinik St. Elisabeth, Müller-Gnadenegg-Weg 4, Neuburg an der Donau, Germany. 7Department of Anesthesiology, Amsterdam UMC, University of Amsterdam, Meibergdreef 9, Amsterdam, the Netherlands. ${ }^{8}$ Research in Education, Amsterdam UMC, Vrije Universiteit Amsterdam, De Boelelaan 1117, Amsterdam, the Netherlands.

\section{Received: 18 July 2020 Accepted: 9 March 2021} Published online: 25 March 2021

\section{References}

1. Fernandez R, Kozlowski SW, Shapiro MJ, Salas E. Toward a definition of teamwork in emergency medicine. Acad Emerg Med. 2008;15(11):1104-12. https://doi.org/10.1111/j.1553-2712.2008.00250.x

2. Link Mark S, Berkow Lauren C, Kudenchuk Peter J, Halperin Henry R, Hess Erik P, Moitra Vivek K, et al. Part 7: Adult Advanced Cardiovascular Life Support. Circulation. 2015;132(18_suppl_2):S444-S64. https://doi.org/10.11 61/CIR.0000000000000261.

3. Hunziker S, Johansson AC, Tschan F, Semmer NK, Rock L, Howell MD, Marsch S. Teamwork and leadership in cardiopulmonary resuscitation. J Am Coll Cardiol. 2011;57(24):2381-8. https://doi.org/10.1016/j.jacc.2011.03.017.

4. Krage R, Zwaan L, Len LTS, Kolenbrander MW, van Groeningen D, Loer SA, et al. Relationship between non-technical skills and technical performance during cardiopulmonary resuscitation: does stress have an influence? Emerg Med J. 2017;34(11):728-33. https://doi.org/10.1136/emermed-2016-205754.

5. Blascovich J. Challenge and threat. Handbook of approach and avoidance motivation. New York: Psychology Press; 2008. p. 431-45.

6. Vine SJ, Moore LJ, Wilson MR. An Integrative Framework of Stress, Attention and Visuomotor Performance. Front Psychol. 2016;7:1671. https://doi.org/1 $0.3389 /$ fpsyg. 2016.01671

7. Leblanc VR. The effects of acute stress on performance: implications for health professions education. Acad Med. 2009;84(SUPPL. 10):S25-33. https:// doi.org/10.1097/ACM.0b013e3181b37b8f.

8. Arora S, Sevdalis N, Nestel D, Woloshynowych M, Darzi A, Kneebone R. The impact of stress on surgical performance: a systematic review of the literature. Surgery. 2010;147(3):318-30, 30.e1-6. https://doi.org/10.1016/j. surg.2009.10.007.

9. Hunziker S, Laschinger L, Portmann-Schwarz S, Semmer NK, Tschan F, Marsch S. Perceived stress and team performance during a simulated resuscitation. Intensive Care Med. 2011;37(9):1473-9. https://doi.org/10.1007/ s00134-011-2277-2.

10. Piquette D, Tarshis J, Sinuff T, Fowler RA, Pinto R, Leblanc VR. Impact of acute stress on resident performance during simulated resuscitation episodes: a prospective randomized cross-over study. Teach Learn Med. 2014;26(1):9-16. https://doi.org/10.1080/10401334.2014.859932.

11. Rosen MA, DiazGranados D, Dietz AS, Benishek LE, Thompson D, Pronovost PJ, Weaver SJ. Teamwork in healthcare: key discoveries enabling safer, highquality care. Am Psychologist. 2018;73(4):433-50. https://doi.org/10.1037/a mp0000298.

12. King HB, Battles J, Baker DP, Alonso A, Salas E, Webster J, et al. TeamSTEPPS ${ }^{\mathrm{Tm}}$ : Team Strategies and Tools to Enhance Performance and Patient Safety. In: Henriksen K, Battles JB, Keyes MA, Grady ML, editors. Advances in Patient Safety: New Directions and Alternative Approaches (Vol 3: Performance and Tools). Rockville: Advances in Patient Safety; 2008.

13. Müller MP, Hänsel M, Fichtner A, Hardt F, Weber S, Kirschbaum C, Rüder S, Walcher $F$, Koch $T$, Eich C. Excellence in performance and stress reduction during two different full scale simulator training courses: a pilot study. Resuscitation. 2009;80(8):919-24. https://doi.org/10.1016/j.resuscitation.2009. 04.027.

14. Ignacio J, Scherpbier A, Dolmans D, Rethans J-J, Liaw SY. Mental rehearsal strategy for stress management and performance in simulations. Clin Simul Nursing. 2017;13(7):295-302. https://doi.org/10.1016/j.ecns.2017.04.005

15. Lauria MJ, Gallo IA, Rush S, Brooks J, Spiegel R, Weingart SD. Psychological skills to improve emergency care Providers' performance under stress. Ann Emerg Med. 2017;70(6):884-90. https://doi.org/10.1016/j.annemergmed.2017. 03.018 .

16. Ghazali DA, Ragot S, Breque C, Guechi Y, Boureau-Voultoury A, Petitpas F, et al. Randomized controlled trial of multidisciplinary team stress and performance in immersive simulation for management of infant in shock: study protocol. Scand J Trauma Resuscitat Emerg Med. 2016;24:36. https:// doi.org/10.1186/s13049-016-0229-0.

17. Buljac-Samardzic M, Doekhie KD, van Wijngaarden JDH. Interventions to improve team effectiveness within health care: a systematic review of the past decade. Hum Resour Health. 2020;18(1):2. https://doi.org/10.1186/s12 960-019-0411-3.

18. Marlow SL, Hughes AM, Sonesh SC, Gregory ME, Lacerenza CN, Benishek LE, Woods AL, Hernandez C, Salas E. A systematic review of team training in health care: ten questions. Jt Comm J Qual Patient Saf. 2017;43(4):197-204. https://doi.org/10.1016/j.jcjq.2016.12.004

19. Gross B, Rusin L, Kiesewetter J, Zottmann JM, Fischer MR, Prückner S, Zech A. Crew resource management training in healthcare: a systematic review of intervention design, training conditions and evaluation. BMJ Open. 2019; 9(2):e025247. https://doi.org/10.1136/bmjopen-2018-025247.

20. Carne B, Kennedy M, Gray T. Review article: crisis resource management in emergency medicine. Emerg Med Austr. 2012;24(1):7-13. https://doi.org/1 0.1111/j.1742-6723.2011.01495.x.

21. Salas E, Rosen MA. Building high reliability teams: progress and some reflections on teamwork training. BMJ Qual Saf. 2013;22(5):369-73. https:// doi.org/10.1136/bmjas-2013-002015.

22. Weaver SJ, Dy SM, Rosen MA. Team-training in healthcare: a narrative synthesis of the literature. BMJ Qual Saf. 2014;23(5):359-72. https://doi.org/1 0.1136/bmjas-2013-001848.

23. Institute TJB. Joanna Briggs Institute Reviewers' Manual: 2015 edition / supplement. 2015

24. Munn Z, Peters MDJ, Stern C, Tufanaru C, McArthur A, Aromataris E Systematic review or scoping review? Guidance for authors when choosing between a systematic or scoping review approach. BMC Med Res Methodol. 2018:18(1):143. https://doi.org/10.1186/s12874-018-0611-x.

25. Arksey H, O'Malley L. Scoping studies: towards a methodological framework Int J Soc Res Methodol. 2005:8(1):19-32. https://doi.org/10.1080/1364557032 000119616.

26. Levac D, Colquhoun H, O'Brien KK. Scoping studies: advancing the methodology. Implement Sci. 2010;5(1):69. https://doi.org/10.1186/17485908-5-69.

27. Moher D, Liberati A, Tetzlaff J, Altman DG. Preferred reporting items for systematic reviews and meta-analyses: the PRISMA statement. BMJ. 2009; 339:b2535. https://doi.org/10.1136/bmj.b2535

28. Tricco AC, Lillie E, Zarin W, O'Brien KK, Colquhoun H, Levac D, Moher D, Peters MDJ, Horsley T, Weeks L, Hempel S, Akl EA, Chang C, McGowan J, Stewart L, Hartling L, Aldcroft A, Wilson MG, Garritty C, Lewin S, Godfrey CM, Macdonald MT, Langlois EV, Soares-Weiser K, Moriarty J, Clifford T, Tunçalp Ö, Straus SE. PRISMA extension for scoping reviews (PRISMA-SCR): checklist and explanation. Ann Intern Med. 2018;169(7):467-73. https://doi.org/10.732 6/M18-0850.

29. Research NIfH. International prospective register of systematic reviews Available from: https://www.crd.york.ac.uk/prospero/.

30. Peters MDJ, Marnie C, Tricco AC, Pollock D, Munn Z, Alexander L, et al. Updated methodological guidance for the conduct of scoping reviews. JBI Evid Synthesis. 2020;18(10):2119-26. https://doi.org/10.11124/JBIES-2000167.

31. Hawker S, Payne S, Kerr C, Hardey M, Powell J. Appraising the evidence: reviewing disparate data systematically. Qual Health Res. 2002;12(9):1284-99. https://doi.org/10.1177/1049732302238251.

32. National Institute for Health and Care Excellence. Methods for the development of nice public health guidance. 2012. Available from: https:// www.nice.org.uk/process/pmg4/chapter/appendix-e-algorithm-for-cla ssifying-quantitative-experimental-and-observational-study-designs.

33. Gardner HK. Performance pressure as a double-edged sword: enhancing team motivation but undermining the use of team knowledge. Adm Sci Q. 2012:57(1):1-46. https://doi.org/10.1177/0001839212446454.

34. Savelsbergh C, Gevers JMP, van der Heijden B, Poell RF. Team role stress: relationships with team learning and performance in project teams. Group Org Manag. 2012;37(1):67-100. https://doi.org/10.1177/1059601111431977.

35. Gervits F, Eberhard K, Scheutz M. Team communication as a collaborative process. Front Robot Al. 2016;3. https://doi.org/10.3389/ frobt.2016.00062.

36. Long J, Zang Z, Chen C. The Benefits Of Repeated Collaboration For Team Performance In A Chinese Context. Soc Behav Personal. 2014:42(9):1507-20. https://doi.org/10.2224/sbp.2014.42.9.1507. 
37. Bourgeon L, Valot C, Navarro C. Communication and flexibility in aircrews facing unexpected and risky situations. Int J Aviat Psychol. 2013;23(4):289305. https://doi.org/10.1080/10508414.2013.833744.

38. Ellis APJ, Pearsall MJ. Reducing the negative effects of stress in teams through cross-training: a job demands-resources model. Group Dynam Theory Res Pract. 2011;15(1):16-31. https://doi.org/10.1037/a0021070.

39. Kaplan S, Laport K, Waller MJ. The role of positive affectivity in team effectiveness during crises. J Organ Behav. 2013;34(4):473-91. https://doi. org/10.1002/job.1817.

40. Pearsall MJ, Ellis APJ, Stein JH. Coping with challenge and hindrance stressors in teams: Behavioral, cognitive, and affective outcomes. Organ Behav Hum Decis Process. 2009;109(1):18-28. https://doi.org/10.1016/j. obhdp.2009.02.002.

41. Price TF, LaFiandra M. The perception of team engagement reduces stress induced situation awareness overconfidence and risk-taking. Cogn Syst Res. 2017;46:52-60. https://doi.org/10.1016/j.cogsys.2017.02.004.

42. Stachowski AA, Kaplan SA, Waller MJ. The benefits of flexible team interaction during crises. J Appl Psychol. 2009;94(6):1536-43. https://doi. org/10.1037/a0016903.

43. Maruping LM, Venkatesh V, Thatcher SMB, Patel PC. Folding under pressure or rising to the occasion? Perceived time pressure and the moderating role of team temporal leadership. Acad Manag J. 2015;58(5):1313-33. https://doi. org/10.5465/amj.2012.0468

44. Espevik R, Olsen OK. A new model for understanding teamwork onboard: the shipmate model. Int Marit Health. 2013;64(2):89-94.

45. Espevik R, Johnsen BH, Eid J. Outcomes of shared mental models of team members in cross training and high-intensity simulations. J Cogn Eng Decis Mak. 2011;5(4):352-77. https://doi.org/10.1177/1555343411424695.

46. Xu J, Montague E. An experimental study on individual and group affect in multi-tasking teams. Ergonomics. 2018;62(3):376-90. https://doi.org/10.1080/ 00140139.2018 .1544378$.

47. Wang DX, Gao Q, Tan HB, Liu ZP, Zhou LW, Jia L, Li Z. Coordination breakdowns in nuclear power plant control rooms: cause identification and behaviour-sequence analysis. Ergonomics. 2020;63(6):660-81. https://doi. org/10.1080/00140139.2020.1755060.

48. Austin JR. Transactive memory in organizational groups: the effects of content, consensus, specialization, and accuracy on group performance. J Appl Psychol. 2003;88(5):866-78. https://doi.org/10.1037/0021-9010.88.5.866.

49. Riskin A, Erez A, Foulk TA, Kugelman A, Gover A, Shoris I, Riskin KS, Bamberger PA. The impact of rudeness on medical team performance: a randomized trial. Pediatrics. 2015;136(3):487-95. https://doi.org/10.1542/ peds.2015-1385.

50. Katz D, Blasius K, Isaak R, Lipps J, Kushelev M, Goldberg A, et al. Exposure to incivility hinders clinical performance in a simulated operative crisis. BM Qual Saf. 2019;28(9):750. https://doi.org/10.1136/bmjqs-2019-009598.

51. DeChurch LA, Mesmer-Magnus JR. The cognitive underpinnings of effective teamwork: a meta-analysis. J Appl Psychol. 2010;95(1):32-53. https://doi. org/10.1037/a0017328

52. Fernandez R, Shah S, Rosenman ED, Kozlowski SWJ, Parker SH, Grand JA Developing team cognition: a role for simulation. Simul Healthc. 2017;12(2): 96-103. https://doi.org/10.1097/SIH.0000000000000200.

53. Salas E, Rosen MA, Burke CS, Nicholson D, Howse WR. Markers for enhancing team cognition in complex environments: the power of team performance diagnosis. Aviat Space Environ Med. 2007;78(5 Suppl):77-85.

54. Gardner AK, Scott DJ, AbdelFattah KR. Do great teams think alike? An examination of team mental models and their impact on team performance. Surgery. 2017;161(5):1203-8. https://doi.org/10.1016/j.surg.201 6.11.010.

55. Gardner AK, Ahmed RA. Transforming trauma teams through Transactive memory: can simulation enhance performance? Simul Gaming. 2014;45(3): 356-70. https://doi.org/10.1177/1046878114547836.

56. Marks MA, Sabella MJ, Burke CS, Zaccaro SJ. The impact of cross-training on team effectiveness. J Appl Psychol. 2002;87(1):3-13. https://doi.org/10.1037/ 0021-9010.87.1.3.

57. Salas E, DiazGranados D, Klein C, Burke CS, Stagl KC, Goodwin GF, Halpin SM. Does team training improve team performance? Meta Anal Human Fact. 2008;50(6):903-33. https://doi.org/10.1518/001872008X375009.

58. Engum SA, Jeffries PR. Interdisciplinary collisions: bringing healthcare professionals together. Collegian. 2012;19(3):145-51. https://doi.org/10.1016/ j.colegn.2012.05.005
59. Floren LC, Donesky D, Whitaker E, Irby DM, Ten Cate O, O'Brien BC. Are we on the same page? Shared mental models to support clinical teamwork among health professions learners: a scoping review. Acad Med. 2018;93(3): 498-509. https://doi.org/10.1097/ACM.0000000000002019.

60. Volpe CE, Cannon-Bowers JA, Salas E, Spector PE. The impact of crosstraining on team functioning: an empirical investigation. Hum Factors. 1996; 38(1):87-100. https://doi.org/10.1518/001872096778940741.

61. O'Dea A, O'Connor P, Keogh I. A meta-analysis of the effectiveness of crew resource management training in acute care domains. Postgrad Med J. 2014;90(1070):699-708. https://doi.org/10.1136/postgradmedj-2014-132800 Epub 2014 Nov 4.

62. Kemper PF, de Bruijne M, van Dyck C, So RL, Tangkau P, Wagner C. Crew resource management training in the intensive care unit. A multisite controlled before-after study. BMJ Qual Saf. 2016;25(8):577-87. https://doi. org/10.1136/bmjqs-2015-003994.

63. Murphy M, Curtis K, Lam MK, Palmer CS, Hsu J, McCloughen A. Simulationbased multidisciplinary team training decreases time to critical operations for trauma patients. Injury. 2018;49(5):953-8. https://doi.org/10.1016/j.injury.2 018.01.009.

64. Nallamothu BK, Guetterman TC, Harrod M, Kellenberg JE, Lehrich JL, Kronick SL, Krein SL, Iwashyna TJ, Saint S, Chan PS. How do resuscitation teams at top-performing hospitals for in-hospital cardiac arrest succeed? Circulation. 2018;138(2):154-63. https://doi.org/10.1161/CIRCULATIONAHA.118.033674.

65. Josey K, Smith ML, Kayani AS, Young G, Kasperski MD, Farrer P, Gerkin R Theodorou A, Raschke RA. Hospitals with more-active participation in conducting standardized in-situ mock codes have improved survival after in-hospital cardiopulmonary arrest. Resuscitation. 2018;133:47-52. https:// doi.org/10.1016/j.resuscitation.2018.09.020.

66. Reid C, Brindley P, Hicks C, Carley S, Richmond C, Lauria M, et al. Zero point survey: a multidisciplinary idea to STEP UP resuscitation effectiveness. Clin Exp Emerg Med. 2018;5(3):139-43. https://doi.org/10.15441/ceem.17.269.

67. Groombridge CJ, Kim Y, Maini A, Smit DV, Fitzgerald MC. Stress and decision-making in resuscitation: a systematic review. Resuscitation. 2019; 144:115-22. https://doi.org/10.1016/j.resuscitation.2019.09.023.

\section{Publisher's Note}

Springer Nature remains neutral with regard to jurisdictional claims in published maps and institutional affiliations.

Ready to submit your research? Choose BMC and benefit from

- fast, convenient online submission

- thorough peer review by experienced researchers in your field

- rapid publication on acceptance

- support for research data, including large and complex data types

- gold Open Access which fosters wider collaboration and increased citations

- maximum visibility for your research: over $100 \mathrm{M}$ website views per year

At BMC, research is always in progress.

Learn more biomedcentral.com/submissions 